\title{
PEMBINAAN TATA BAHASA DAN TATA BENTUK SURAT-MENYURAT INDONESIA PADA KELOMPOK BIDANG EKSTRAKURIKULER SMA MUHAMMADIYAH KEDAWUNG KABUPATEN CIREBON
}

\author{
Tri Pujiatna \\ Jurusan Pendidikan Bahasa dan Sastra Indonesia,Universitas Swadaya Gunung Djati, Cirebon, Indonesia \\ *Penulis korespondensi: tpujiatna@gmail.com
}

\begin{abstract}
Abstrak
Kegiatan surat-menyurat memiliki peran penting dalam menyampaikan sebuah informasi. Agar komunikasi berjalan dengan baik, maka isi surat harus jelas kepada pihak penerima surat. Untuk mencapai tujuan itu, maka dibutuhkan tata kelola penulisan surat untuk memudahkan timbal balik surat dalam pembuatan. Surat akan terasa baik apabila bahasa yang digunakan menggunakan bahasa Indonesia yang baik dan benar sesuai dengan pedoman ejaan. Bahasa yang digunakan di dalam kegiatan surat-menyurat harus efektif, wajar, logis, hemat, cermat, sopan, dan menarik. Hal tersebut harus diperhatikan mengingat ruang tulis dalam surat terbatas. Tata bentuk surat tidak kalah pentingnya. Dalam kegiatan surat-menyurat Indonesia mengenal beberapa bentuk surat berdasarkan tata bentuknya, di antaranya: bentuk lurus penuh, bentuk lurus, bentuk setengah lurus, bentuk bertakuk, bentuk Indonesia lama, bentuk Indonesia baru, bentuk menggantung. Oleh karena itu, perlu adanya pembinaan terhadap tata kelola surat-menyurat Indonesia. Melalui teknik pendampingan,tanya jawab serta latihan, pengabdian ini menghasilkan suatu pemahaman pada proses penyusunan serta penulisan surat yang sesuai dengan kaidah bentuk dan tata bahasa surat-menyurat pada kelompok bidang ekstrakurikuler SMA Muhammadiyah Kedawung Kabupaten Cirebon.
\end{abstract}

Kata Kunci: Surat Bahasa Indonesia; Surat-menyurat Indonesia; Tata Bahasa Surat Indonesia; Tata Bentuk Surat Indonesia.

\begin{abstract}
Mailing activities have an important role in conveying information. In order for communication to run well, the contents of the letter must be clear to the recipient of the letter. To achieve this goal, the management of permits is needed to facilitate reciprocity of letters in the making. The letter will feel good translated using good and correct Indonesian in accordance with spelling instructions. The language used in correspondence activities must be effective, reasonable, logical, thrifty, careful, polite, and interesting. This must be noted in the limited space for writing space. The form of letters is no less important. In Indonesian correspondence activities recognize several forms of letters according to their form, here: full straight forms, straight forms, straight forms, curved forms, old Indonesian forms, new Indonesian forms, Indonesian forms. Therefore, there is a need for guidance on Indonesian correspondence governance. Through mentoring, question and answer and practice techniques, this service produces an understanding of the manufacturing process as well as renewing letters in accordance with the rules of letter-form and grammar in the extracurricular field group of Muhammadiyah Kedawung High School, Districts Cirebon.
\end{abstract}

Keywords: Indonesian Letter; Indonesian correspondence; Indonesian Letters of Grammar; Forms of Indonesian Letters.

\section{PENDAHULUAN}

Surat-menyurat merupakan salah satu bentuk komunikasi tulis. Sebagai bentuk komunikasi, pesan yang disampaikan harus dapat diterima dengan baik oleh para pembacanya. Kegiatan surat-menyurat tidak hanya menerima dan mengirim surat saja, tetapi berfungsi surat sebagai media komunikasi dan bahan bukti hitam di atas putih dalam sebuah organisasi baik pemerintahan maupun swasta. Purwanto (2011 : 178) "surat adalah sarana komunikasi yang digunakan untuk menyampaikan informasi tertulis oleh suatu pihak kepada pihak lain baik yang berkaitan dengan bisnis maupun non bisnis." Artinya kegiatan surat-menyurat dilakukan dalam bentuk komunikasi tulis dengan cara saling berkirim surat yang isinya berkaitan dengan sebuah informasi antara penerima dan pengirim surat. Hal ini sejalan dengan Syafriadi (2015) menjelaskan bahwa surat merupalam salah satu media komunikasi yang sangat penting dalam suatu instansi dan intitusi, perusahaan maupun bentuk organisasi yang lain, baik 
untuk berkomunikasi dengan pihak-pihak di luar organisasi (eksternal) maupun untuk berkomunikasi dalam lingkup organisasi itu sendiri.

Selanjutnya, Prawono \& Pamungkas (2015) Surat adalah informasi tertulis yang dapat dipergunakan sebagai alat komuniasi tulis yang dibuat dengan prasayat tertentu yang khusus yang berlaku untuk surat menyurat. Artinya bahwa kegiatan surat-menyurat memiliki peran penting dalam menyampaikan sebuah informasi. Agar komunikasi berjalan dengan baik, maka isi surat yang ingin disampaikan harus jelas kepada pihak penerima surat. Untuk mencapai tujuan itu, maka dibutuhkan tata kelola penulisan surat untuk memudahkan timbal balik.

Pembuatan surat pada dasarnya merupakan suatu cara pengaturan atau cara penyampaian informasi secara logis dan sistematis. Oleh karena itu, ada prasyarat yang harus diperhatikan di dalam menulis surat, yaitu a) penggunaan kertas, b) penggunaan model atau bentuk, c) penggunaan kode dan notasi, d) pemakaian bahasa yang khas, dan d) pencantuman tanda tangan. (Finoza, 1991:4).

Surat akan terasa baik apabila bahasa yang digunakan menggunakan bahasa Indonesia yang baik dan benar sesuai dengan kaidah ejaan. Sejalan dengan hal tersebut, Pujiatna (2018) penggunaan kaidah ejaan bahasa Indonesia dengan tepat akan mempengaruhi makna yang diterima oleh pembaca. Oleh karena itu, Penggunaan bahasa dalam surat harus efektif, wajar, logis, hemat, cermat, sopan, dan menarik. Hal tersebut harus diperhatikan mengingat ruang tulis dalam surat terbatas. Berikut beberapa syarat bahasa surat ;

1. Surat ditulis dalam bentuk yang menarik, dan tersusun sesuai dengan peraturan surat menyurat.

2. Setiap kalimat dalam surat harus berguna, bermakna, maka tidak boleh memakai kalimat yang berbelit-belit.

3. Hindarkan singkatan yang tidak perlu terutama mengarang singkatan sendiri.

4. Nada surat harus sopan dan bijaksana serta hormat dan simpatik.

5. Surat jangan terlalu panjang.

6. Surat harus bersih, rapi.

Selain itu, tata bentuk surat tidak kalah pentingnya. Tata bentuk surat Indonesia pada tiap-tiap organisasi baik pemerintah atau swasta merupakan suatu ciri khas penulisan surat. Bentuk surat adalah tata letak atau posisi bagian-bagian surat, masing-masing bagian surat itu mempunyai posisi tertentu sesuai dengan fungsi dan peranan terutama sebagai petunjuk atau identifikasi untuk memproses surat tersebut. Finoza (1991:15) "Penempatan bagaian-bagian surat pada posisi tertentu akan membentuk model (style) tertentu." Artinya bentuk surat yang satu dengan yang lain akan berbeda sesuai dengan kebiasaan instansi pemakainya. Adapun bentuk-bentuk surat-menyurat Indonesia sebagai berikut; a. Bentuk Indonesia lama (official style),

Bentuk surat resmi ini mirip dengan bentuk setengah lurus, hanya berbeda dalam alamat surat. Alamat surat pada bentuk resmi Indonesia di sebelah kanan di bawah tanggal surat. Jelasnya, jika alamat pada bentuk setengah lurus digeser ke kanan berubahlah bentuknya menjadi bentuk Indonesia lama. Bentuk ini yang paling banyak digunakan dalam suratmenyurat bahasa Indonesia.

b. Bentuk Indonesia baru (new official style),

Bentuk resmi Indonesia baru merupakan variasi bentuk setengah lurus atau bentuk resmi Indonesia. Bedanya dengan bentuk setengah lurus terletak pada penulisan salam penutup.

c. Bentuk Lurus Penuh (full block style),

Ditinjau dari segi teknik pengertian bentuk lurus penuh paling efisien dibandingkan dengan bentukbentuk lainnya karena hanya sekali memasang, pasak baris pinggirseluruh mulai dari kiri, tanggal, nomor, hal, salam pembuka, sampai kepada salam penutup tidak perlu sering menghitung hentakan, hanya kita harus jarak (spasi) supaya tidak kelihatan bertumpuk.

d. Bentuk Lurus (block style),

Perbedaan dengan bentuk lurus penuh adalah dimana pada bentuk lurus, tanggal ditulis sebelah kanan, sejajar dengan nomor surat, kemudian salam penutup,dan tanda tangan penanggung jawab berada disebelah kanan juga, sehingga bagian bawah kiri agak leluasa untuk dipakai tembusan bila surat itu ada salinan yang harus dikirimkan, bentuk ini adalah model Amerika.

e. Bentuk Setengah Lurus (semi block style,)

Penulisan hampir sama dengan bentuk lurus, hanya bedanya bentuk setengah lurus pada alinea pertama harus menjorok kedalam kurang lebih 5 spasi, begitu seterusnya. Untuk alinea-alinea yang baru dan bentuk ini banyak sekali digunakan oleh perusahaan-perusahaan.

f. Bentuk Bertakuk (indented style),

Pada dasarnya bentuk ini menyerupai surat bentuk setengah lurus. Perbedaan hanya terdapat pada penulisan alamat tujuan surat yang ditulis secara bergerigi. Ciri khas dari surat ini pengetikan alamat tempat dan tanggal, salam penutup, nama dan jabatan diketik pada sebelah kanan, sedangkan pada isi surat di setiap pergantian alinea baru, pengetikannya masuk ke dalam sebanyak lima hentakan.

g. Bentuk Menggantung (hanging paragraph style) Bentuk ini jarang digunakan baik oleh perusahaan maupun dinas pemerintahan. Alamat dalam ditulis sebelah kiri, alinea pertama dan setiap alinea baru ditulis dari baris pinggir, dan kalimat-kalimat bersambung ditulis ditengah kurang lebih 10 spasi dari pinggir sehingga kelihatannya jadi menggantung.

Pada umumnya surat terdiri atas empat komponen utama yaitu kop surat (kepala surat), leher surat, badan surat, dan kaki surat. Setiap komponen memiliki fungsi sendiri dalam memperkenalkan dan 
mengomunikasikan pesan si pengirim. Berikut bagianbagian surat menurut Soedjito dan Solchan (2004 : 3863); 1) Kepala Surat; 2) Tanggal surat; 3) Nomor surat; 4) Perihal surat; 5) Lampiran; 6) Alamat yang dituju; 7) Salam pembuka; 8) Kalimat pembuka; 9) Isi surat; 10) Kalimat penutup; 11) Salam penutup; 12) Tembusan.

Pelaksanaan kegiatan ini didasari atas penggunaan tata bentuk dan tata bahasa surat yang digunakan kelompok ekstrakurikuler SMA Muhammadiyah Kedawung Kabupaten Cirebon belum mengacu pada standar penyusunan dan penulisan surat. Selain itu, permintaan dari pihak sekolah serta pembina Osis (IPM)/wakasek bidang kesiswaan perlu adanya pembinaan dari ahli eksternal. Melalui kegiatan ini, diharapkan dapat meningkatkan wawasan serta keterampilan ketua, sekretaris dan anggota kelompok pada bidang ekstrakurikuler SMA Muhammadiyah Kedawung Kabupaten Cirebon dalam penyusunan serta penulisan surat-menyurat.

\section{METODE PELAKSANAAN}

Program pengabdian masyarakat ini menggunakan metode langsung. Metode yang digunakan meliputi teknik pendampingan, tanya jawab, dan latihan dalam tata kelola surat-menyurat Indonesia. Alasan menggunakan metode tersebut karena mudah untuk digunakan. Adapun prosedur kerja dalam kegiatan ini sebagai berikut.

1. Melakukan studi awal, berupa menganalisis tata bahasa dan tata bentuk surat yang digunakan oleh kelompok bidang ekstrakurikuler SMA Muhammadiyah Kedawung Kabupaten Cirebon.

2. Mengadakan koordinasi dengan Pihak sekolah dan pembina Osis (IPM) SMA Muhammdiyah Kedawung Kabupaten Cirebon untuk menentukan waktu pelaksanaan pembinaan tata bahasa dan tata bentuk surat-menyurat Indonesia.

3. Pelaksanaan pembinaan tata bahasa dan tata bentuk surat-menyurat Indonesia. Program pembinaan dibagi dua sesi yaitu, sesi teori dan sesi praktik.

\section{HASIL DAN PEMBAHASAN}

Hasil kegiatan pembinaan tata bentuk dan tata bahasa surat-menyurat Indonesia yang diikuti sebanyak 69 peserta, sebagai berikut;

1. Melalui kegiatan pembinaan, dengan teknik pendampingan, tanya jawab, dan latihan dapat berjalan dengan baik karena mudah diterapakan serta dipahami oleh peserta. Hal ini dapat dilihat saat pemaparan materi tentang tata bentuk dan tata bahasa surat, peserta dengan mudah memahami materi tersebut. Pemateri juga mengkombinasikan dengan metode tanya jawab guna mengetahui sejauh mana para peserta memahami materi tentang tata bentuk dan tata bahasa surat-menyurat Indonesia dengan memberikan beberapa pertanyaan secara lisan sekait dengan kaidah penyusunan serta penulisan surat dengan menampilkan beberapa contoh bentuk dan bahasa surat pada slide power point.
2. Hasil pembinaan yang dilaksanakan, peserta sangat antusias mengikuti kegiatan ini. Hal ini merupakan kegiatan pembinaan yang kali pertama diterima oleh peserta. Kegiatan surat-menyurat yang dilakukan oleh organisasi di SMA Muhammadiyah Kedawung sebelum mendapatkan kegiatan pembinaan hanya dengan melihat dari contoh yang sudah ada. Proses menulis surat yang dilakukan secara turun-menurun dengan menulisan ulang, dengan mengubah tanggal, perihal, kepada yang dituju, dan waktu pelaksanaan. Bentuk surat yang digunakan dalam kegiatan berorganisasi di lingkungan SMA Muhammadiyah Kedawung pun tidak mengikuti kaidah penulisan surat-menyurat Indonesia. Namun, setelah mengikuti kegiatan ini, peserta pembinaan mulai menunjukan pemahaman terhadap tata bahasa dan tata bentuk surat-menyurat Indonesia dengan cara memperbaiki kesalahan-kesalahan dalam proses penulisan surat.

3. Monitoring dan evaluasi dilakukan dengan menggunakan teknik latihan. Latihan penulisan surat dengan memberikan sebuah ilustrasi suatu peristiwa kemudian peserta dituntut untuk menulis sebuah surat dengan memperhatikan tata bentuk dan tata bahasa surat. Setelah menerapkan latihan, hasil yang didapat masih terdapat kekeliruan dalam membuat surat yang dibuat oleh organisasi dengan kaidah penulisan surat. Hal ini terjadi karena sudah menjadi kebiasaan yang belum tepat pada peserta dalam penulisan surat yang dilakukan secara berulang-ulang. Adapun kekeliruan penggunaan tata bahasa surat pada kelompok bidang ekstrakurikuler di SMA Muhammadiyah Kedawung Kabupaten Cirebon, seperti pengunaan tanda baca apostrof (') pada kata "Jum 'at" seharusnya "Jumat”. Selain itu, pemborosan penggunaan kata dalam hal yang dituju. "Kepada Yth." seharusnya "Kepada" atau "Yth.", pilih salah satunya. Jika hal yang dituju berupa nama perorangan maka mengunakan kata "Yth.". Jika hal yang dituju berupa pejabat pemerintah/swasta maka mengunakan kata "Kepada". Bertolak pada monitoring dan evaluasi dengan menggunakan teknik latihan pemateri memberikan pemahaman berupa saran perbaikan sekait tata bahasa yang digunakan pada proses penulisan surat. Berikut beberapa saran perbaikan dalam penulisan tata bahasa dan struktur surat. 
Tabel 1: Saran Perbaikan Penulisan Tata Bahasa dan Struktur Surat.

\begin{tabular}{|c|c|}
\hline Tidak taat Asas & Taat Asas \\
\hline $\begin{array}{ll}\text { No. } & \\
\text { Lampiran } & : \\
\text { Hal. } & :\end{array}$ & $\begin{array}{ll}\text { No. } & : \\
\text { Lamp. } & : \\
\text { Hal } & :\end{array}$ \\
\hline Cirebon, 16 Juli 2018 & 16 Juli 2018 \\
\hline $\begin{array}{l}\text { Assalamu'alaikum Wr. Wb., (salam pembuka) } \\
\text { Hormat Kami, (Salam Penutup) }\end{array}$ & $\begin{array}{l}\text { Assalamualaikum Wr. Wb., (salam pembuka) } \\
\text { Wassalamualaikum Wr. Wb. (salam Penutup) }\end{array}$ \\
\hline
\end{tabular}

\begin{tabular}{ll}
\hline Dengan hormat, (salam Pembuka) & Dengan hormat, (salam Pembuka) \\
Wassalamu'alaikum Wr. Wb. (salam Penutup) & Hormat kami/saya, (salam Penutup)
\end{tabular}

\begin{tabular}{lll}
\hline Atas perhatian dan kedatangannya, kami & Atas perhatian Bapak/Ibu/Saudara, kami sampaikan \\
menghaturkan terima kasih yang sebesar-besarnya. & terima kasih.
\end{tabular}

\begin{tabular}{ll}
\hline Kepada Perorangan: & Kepada Perorangan : \\
Yth. Bapak Lukman, S.E. & Yth. Lukman, S.E. \\
Jln. Tuparev No. 70 & Jalan Tuparev No. 70 \\
Cirebon 45411 & Cirebon 45411
\end{tabular}

\begin{tabular}{ll}
\hline Kepada Pejabat Pemerintah/Swasta: & Kepada Pejabat Pemerintah /Swasta: \\
Yth. Bapak Kepala SMA Muhammadiyah & Yth. Kepala SMA Muhammadiyah Kedawung \\
Kedawung & Jalan Tuparev No. 70 \\
Jln. Tuparev No. 70 & Cirebon 45411 \\
Cirebon 45411 &
\end{tabular}

\begin{tabular}{ll}
\hline Kepada Organisasi/Perusahaan : & Kepada Organisasi/Perusahaan : \\
PT Semoga Sukses & PT Semoga Sukses \\
Jln. Tuparev No. 70 & Jln. Tuparev No. 70 \\
Cirebon 45411 & Cirebon 45411
\end{tabular}

\begin{tabular}{ll}
\hline Kepada Pimpinan Perusahaan/organisasi : & Kepada Pimpinan Perusahaan/organisasi : \\
Yth. Manajer Personalia & Yth. Manajer Personalia \\
PT Semoga Sukses & PT Semoga Sukses \\
Jln. Tuparev No. 70 & Jalan Tuparev No. 70 \\
Cirebon 45411 & Cirebon 45411
\end{tabular}

\section{KESIMPULAN}

Tujuan pengabdian ini untuk meningkatkan wawasan serta keterampilan ketua, sekretaris, dan anggota kelompok pada bidang ekstrakurikuler SMA Muhammadiyah Kedawung Kebupaten Cirebon dalam penyusunan serta penulis surat-menyurat. Penggunaan metode langsung, dengan teknik pendampingan, tanya jawab, serta latihan kegiatan berjalan dengan baik dengan total peserta yang mengikuti sebanyak 69 peserta. Para peserta mulai terbuka wawasan terhadap penulisan surat dan mulai menggunakan tata bentuk surat dan tata bahasa pada surat organisasi ekstrakurikuler SMA Muhammadiyah Kedawung Kabupaten Cirebon sehingga surat yang dibuat 
terstandar dan terstruktur sesuai dengan kaidah. Adapun bentuk perbaikan yang dilakukan oleh para peserta dengan mengubah kesalahan penulisan unsur struktur surat dan ejaan bahasa pada surat. Selain itu, hasil pengabdian ini menjadi bekal pengetahuan serta keterampilan bagi peserta dalam kegiatan suratmenyurat di dalam kehidupan bermasyarakat dan berorganisasi.

\section{UCAPAN TERIMA KASIH}

Penulis mengucapkan terima kasih kepada LPM Universitas Swadaya Gunung Jati Cirebon yang telah memberikan dana untuk kegiatan ini. Dan, penulis tidak lupa juga mengucapkan terima kasih kepada Kepala serta Pembinaan Osis (IPM) SMA Muhammadiyah Kedawung yang telah memberikan kepercayaan kepada penulis untuk melaksanakan kegiatan pengabdian ini.

\section{Daftar Pustaka}

Finoza, L. (1991). Aneka Surat Sekretaris dan Bisnis Indonesia Seri Korespondesi. Jakarta: Diksi Mulia.

Prawono, J. A., \& Anton R. P. (2015) Sistem Informasi Pengelolaan Surat-menyurat dan Surat Keluar di STMIK AUB Surakarta. Informatika 2 (1), 2633

Purwanto, D. (2011). Komunikasi Bisnis. Jakarta: Erlangga.

Syafriadi. (2015). Analisis dan Perencanaan Sistem Informasi Pengelolaan Surat pada Universitas Cokroaminoto Palopo. Journal Speed -Sentra Penelitian Engineering dan Edukasi 7(4), 19-27

Soedjito \& Solchan T. W. (2004). Surat Menyurat Resmi Bahasa Indonesia. Bandung: Remaja Rosda Karya.

Pujiatna, T. (2018). Penguasaan Ejaan Bahasa Indonesia dalam Kemampuan Menulis Mahasiswa Baru sebagai Bahan Penyusunan Silabus MKU Bahasa Indonesia Universitas Swadaya Gunung Jati Cirebon. Dieksis 5 (1), 91-99 